\title{
Sensitivity, Specificity and cut-off values for HOMA formula; insulin resistance diagnostic tool in Aguascalientes
}

Tavares-Rodríguez Edgar Jesús*, Ávila-Chávez-Abdón*, Vallín-Orozco César Eduardo*, RosasCabral Alejandro**, Rojas-Terán Jaime Froylán*, Bermúdez-Gómez Humberto*, Ruiz-Ruvalcaba José de Jesús*

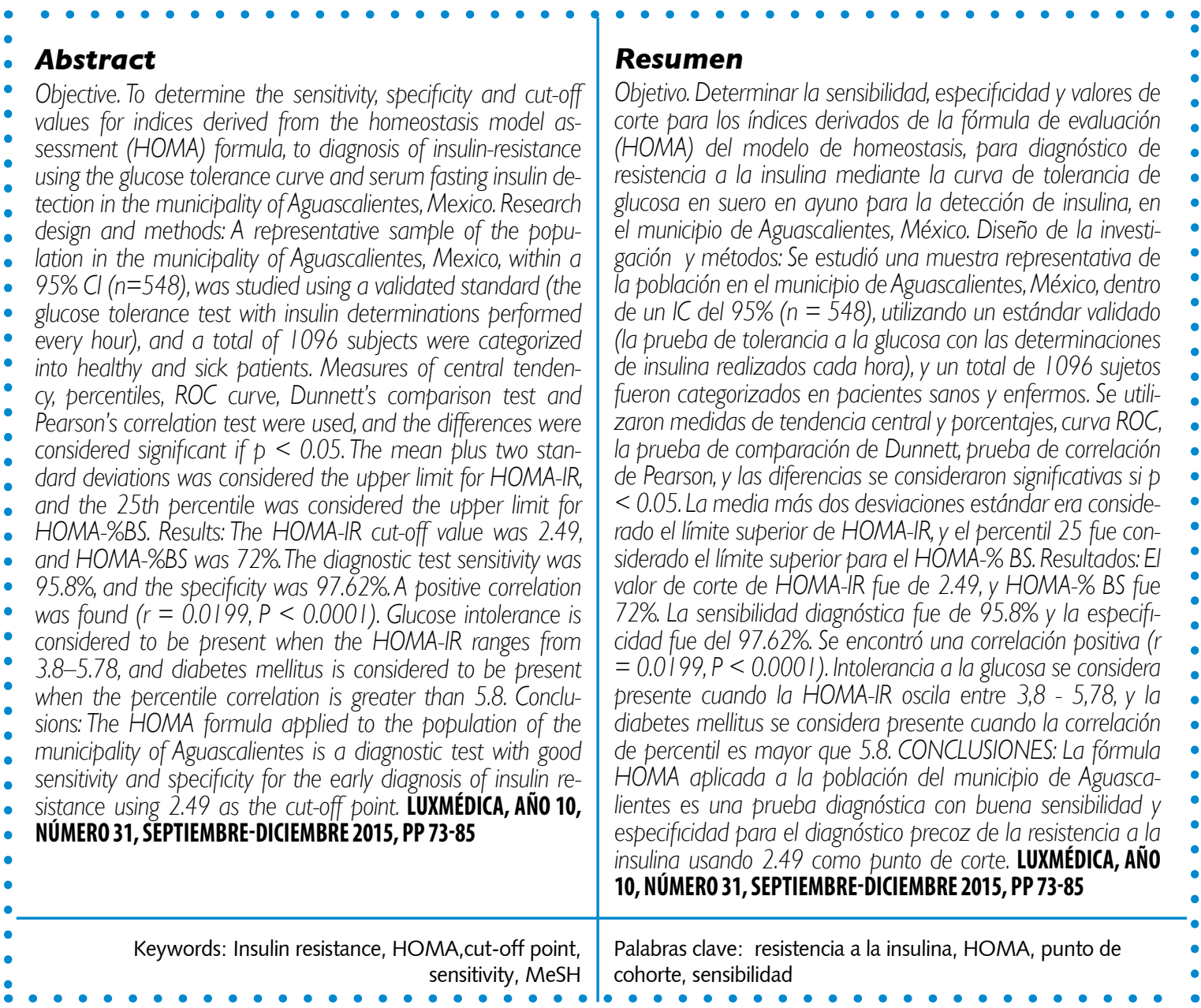

* Estudiantes del noveno semestre de la carrera de Medicina del Centro de Ciencias de la Salud de la Universidad Autónoma de Aguascalientes

** Profesor investigador del Departamento de Medicina del Centro de Ciencias de la Salud de la Universidad Autónoma de Aguascalientes

Fecha de recibido: 30 de septiembre de 2015

Fecha de aceptación: 30 de octubre de 2015

Corresponding Author Alejandro Rosas Cabral Edificio 107 planta alta, Campus universitario. Avenida Universidad 940 Código postal 20131 , Aguascalientes, Aguascalientes, México. Teléfono 9108436. Correo electrónico drrosascabral@gmail.com 


\section{Introducción and theoretical}

Diabetes mellitus is a metabolic disorder that follows the dysfunction of the secretion and/or action of insulin, resulting in hyperglycemia ${ }^{1}$. It is a disease that causes various disabling complications, even when proper medical treatment is undertaken, and it is accompanied by deterioration in the quality of life ${ }^{2}$. There were 171 million people with diabetes mellitus in 2000, and it is estimated that there will be 366 million people with the disease by $2013^{3}$, which explains the greater impetus in the development and implementation of early diagnostic techniques in recent years.

Insulin resistance has become a significant issue at the preventive level. In 1988, Raeven proposed that insulin resistance, together with glucose intolerance, hyperinsulinemia, abnormal plasma lipids and arterial hypertension, formed the $\mathrm{X}$ syndrome ${ }^{4}$, and later called insulin resistance syndrome and more commonly known as metabolic syndrome.

Insulin resistance can be defined as a reduced response of target tissues to insulin, as insulin resistance is linked to hyperinsulinemia. Insulin regulates the sensitivity of its target tissues, and high insulin levels decrease the tissue response. This insensitivity disappears upon removing excess hormone ${ }^{5}$.

Other studies have shown that insulin resistance and the impairment of $\beta$-cell function are among the first disorders in the pathogenesis of type 2 diabetes. Both of these symptoms can be found in people with impairment of glucose tolerance and fasting glucose ${ }^{6,7}$. Therefore, various methodologies have been developed to facilitate the measurement of these parameters, which include insulin resistance, insulin sensitivity and the $\beta$-cell secretion rate.

The hyperglycemic clamp is considered the "gold standard" technique by which calculate insulin sensitivity ${ }^{8,9}$. It is a complicated technique that seeks to raise fasting glucose to $125 \mathrm{mg} / \mathrm{dl}$ and maintain this glucose concentration for two hours using continuous glucose infusion with constant monitoring. It is a difficult method to implement due to the limited availability of the appropriate instruments, and it is only performed in specialized medical centers.

The glucose tolerance test with serum insulin determinations is another method for estimating insulin sensitivity and resistance 10,11. The test consists of a continuous intravenous glucose infusion; blood samples are drawn at 60,120 and 180 minutes, and the glucose and insulin concentrations are measured in each sample. Once the values are obtained, the data are analyzed automatically by Bergman's Minimal Model program ${ }^{12}$.

There are simple methods for the calculation of insulin sensitivity, insulin resistance and even the percentage of functional pancreatic $\beta$-cells up on measuring only fasting glucose and insulin blood levels. 


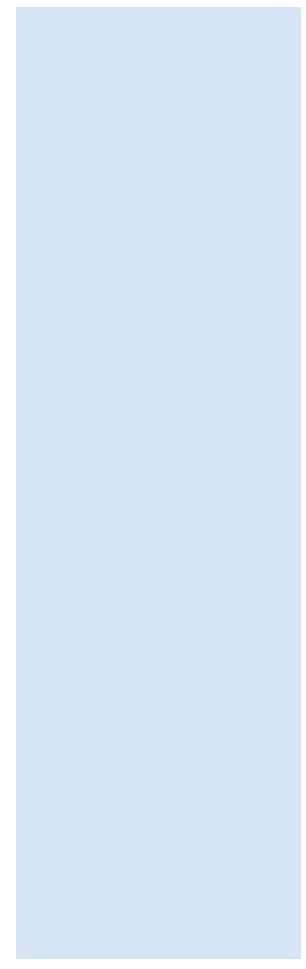

The first method developed is the Homeostasis Model Assessment (HOMA) index described by Turner 13 in 1985, which is an accurate calculation that has been validated against hyperglycemic clamp studies and is therefore widely used. Although the HOMA index initially only calculated insulin resistance (HOMA-IR), later, with the use of computer technology, Levy, Matthews et al. ${ }^{14}$ refined the calculation, making it possible to calculate the tissue sensitivity to insulin ratio $(\mathrm{HOMA}-\% \mathrm{~S})$ and the Beta-secretion ratio (HOMA-\%B). The University of Oxford has software available on the website of the diabetes tests unit (available online at http:// www.dtu.ox.ac.uk) that performs the improved calculation, which is known as HOMA².

The glucose tolerance test with serum insulin determinations still is the gold standard to determinate insulin resistance. HOMA's formula is faster, economical and can be considered as screening test, the test is performed by the serum determination of a fasting glucose and insulin, HOMA-IR, HOMA-\%BS and HOMA-\% IS are obtained using three mathematical calculations. Therefore it was decided to conduct a study to determinate the precision of this test in the diagnosis of insulin resistance, considering that this manifestation is the pre pathogenic state of type 2 diabetes.

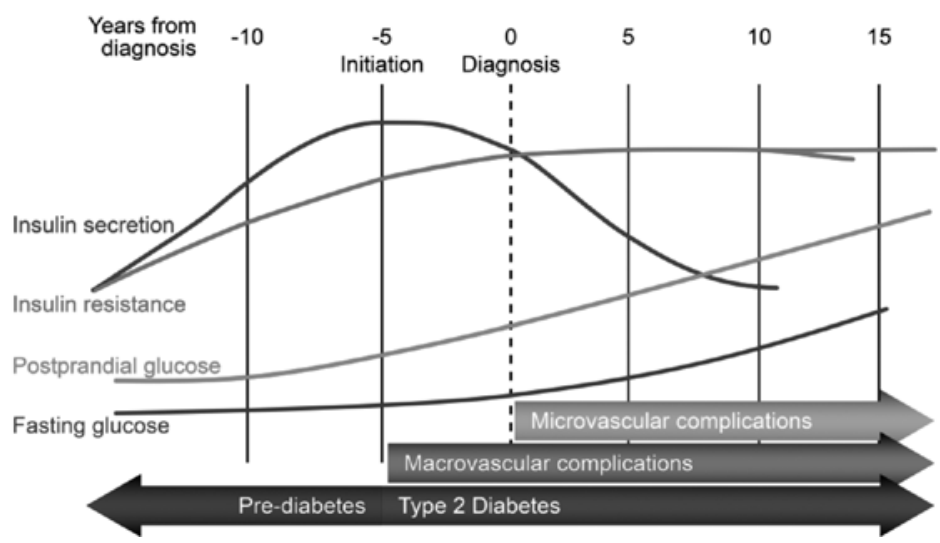

Figure 1.- Shows such plots the natural history of disease.

The aim of our study was to determine the sensitivity, specificity and cut-off values for indices derived from the HOMA formula in the municipality of Aguascalientes. Because the HOMA formula is considered a diagnostic test for insulin re- sistance, and thus an early diagnostic tool for type 2 diabetes, it can also be considered a method for assessing the response to treatment with oral hypoglycemic agents and insulin in patients who have diabetes or are glucose intolerant. 


\section{Research design and methods}

\section{Population Selection}

The study was conducted prospectively with support from the company CMQ L.C. pharmaceuticals in Aguascalientes, Ags, México .It was used to create a database with a youth-adult population aged between 20 and 65 years. The participants underwent glucose tolerance tests, tolerance tests with insulin as control and regular checkups. Their family history and likelihood of having diabetes, among other factors, were recorded.

The control group included volunteers who met the inclusion criteria mentioned below. Each patient was examined, and the following data were collected: age, weight, sex, height, BMI, blood pressure, history of type 2 diabetes, obesity and hypertension. The total population for the municipality of Aguascalientes was analyzed according to the 2010 survey conducted by the Mexican National Institute of Statistics, Geography and Informatics (INEGI, for its initials in Spanish) (available online at http:// www.inegi.org.mx/). The survey included 797,010 people of all ages. The population sample for the age range of the study population was obtained, which consisted of 247,010 people. In total, $48 \%$ of the participants were women, and 52\% were men with a 95\% confidence interval and an accepted error of 0.05 . A population prevalence of $8 \%$ for type 2 diabetes was estimated according to the 2012 National Survey of Health and Nutrition for Aguascalientes (available online at http://www. ensanut.insp. $\mathrm{mx} /$ ), resulting in a proportional sample of $548+/-54$ patients.

The study subjects were informed of the use of their data in the project through an informed consent procedure. The participants were classified as healthy patient (548) and patient with insulin-resistance (548), as determined by a validated standard and performing the glucose tolerance test with insulin determinations. These patients were newly diagnosed and therefore had not received any treatment. The total population sample was 1,096 patients.

The inclusion criteria were as follows: voluntary participation, BMI from 20 to $30 \mathrm{~kg} / \mathrm{m} 2$, waist circumference according to ATP III criteria $<103 \mathrm{~cm}$ for men and $<88 \mathrm{~cm}$ for women, blood pressure < $135 / 85 \mathrm{mmHg}$; no presence of diabetes mellitus by a validated standard and fasting glucose and post-load glucose within $75 \mathrm{~g}$ at 120 min in control subjects; and alterations in the validated standard showing clear signs of disease in sick patients.

In all cases, the patients underwent an unrestricted carbohydrate diet (minimum $300 \mathrm{~g} /$ day) for three days prior to the test according to the WHO standards. They arrived at the lab after a 12hour fast at 08:00 to undergo a glucose tolerance test with a determination of insulin in three hours. Waist diameter was measured below the costal margin and above the iliac crest, and blood pressure was measured by personnel trained according to the technique proposed by the WHO with a manual sphygmomanometer. A blood sample was drawn, in which fasting insulin and glucose were analyzed at 60,120 and $180 \mathrm{~min}$ after glucose load of $75 \mathrm{~g}$ in $375 \mathrm{ml}$ of water was ingested over 5 to 10 minutes. The patients remained at rest and seated in the area designed for glucose tolerance tests developed by CMQ L.C. pharmaceuticals in Aguascalientes.

\section{Analytical Methodology}

Clinical chemistry determinations were performed on an auto-analyzer (A 25 BioSystems). The glucose levels were determined using a glucose oxidase colorimetric method with SPIN reagents (ISO 9001 validated and certified trademark:2008).This method was calibrated with the SPINTROL multi-calibrator and validated with normal and pathological controls (SPIN). Insulin 
blood levels were measured by a chemiluminescence immunoassay with an Abbott Architect i 1000 (Abbott Diagnostic) autoanalyzer and an Inmuno Assay Plus (BioRad, USA) internal quality control.

The population mean plus two standard deviations was used as the upper cut-off value for IR and Youden index using ROC curve. For the $ß$-secretion rates, we used the 25th percentile as the lower cut-off value in the same population, we used the Dunnett test to compare sex and age, using the GraphPad Prism 5.01 data analysis system.

The values were validated using the following HOMA formula: HOMA-IR = ((glucose $\mathrm{mg} / \mathrm{dl}) / 180$ ) (10) (insulin $\mathrm{uU} /$ $\mathrm{ml})) / 22.4, \mathrm{HOMA}-\% \mathrm{BS}=(($ Insulin uU/ $\mathrm{ml})(360)) /(($ glucose $\mathrm{mg} / \mathrm{dl}-63))$, HOMA$\%$ IS $=((1) /($ HOMA-IR $))(100)$. The cutoff values calculated according to whether they were upper or lower cut-off values are shown below.

\section{Results}

\section{Table I}

General characteristic of the study population in Aguascalientes.

\begin{tabular}{|c|c|c|c|c|}
\hline \multirow{3}{*}{$\mathrm{N}=1096$ pacientes } & \multicolumn{4}{|c|}{ VALUE } \\
\hline & \multicolumn{2}{|c|}{$\begin{array}{l}\text { Healtly patient } \\
\qquad(n=548)\end{array}$} & \multicolumn{2}{|c|}{$\begin{array}{l}\text { Insulin-resistance patient } \\
\qquad(n=548)\end{array}$} \\
\hline & MEAN & *SD & MEAN & *SD \\
\hline Age (years) & 40 & 18.62 & 42 & 19.98 \\
\hline Waist diameter $(\mathrm{cm})$ & 74.5 & 6.9 & 88.5 & 14.5 \\
\hline HDL Cholesterol (mg/dl) & 45 & 13.6 & 32 & 12.1 \\
\hline Weight (kg) & 70.6 & 10.9 & 87 & 19.8 \\
\hline $\operatorname{High}(\mathrm{m})$ & 1.66 & 0.20 & 1.69 & 0.22 \\
\hline Diastolic blood pressure $(\mathrm{mmHg})$ & 80 & 2 & 90 & 5.9 \\
\hline Sistolic blood pressure $(\mathrm{mmHg})$ & 110 & 10.5 & 135 & 14.5 \\
\hline Triglycerides (mg/dl) & 139 & 25 & 198 & 35 \\
\hline Basal glucose $(\mathrm{mg} / \mathrm{dl})$ & 89 & 5 & 120 & 23.1 \\
\hline Glucose at $60 \mathrm{~min}(\mathrm{mg} / \mathrm{dl})$ & 125 & 10.8 & 169 & 25.7 \\
\hline Glucose at $120 \mathrm{~min}(\mathrm{mg} / \mathrm{dl})$ & 101 & 9.6 & 132 & 20.1 \\
\hline Glucose at $180 \mathrm{~min}(\mathrm{mg} / \mathrm{dl})$ & 85 & 8.7 & 120 & 18.6 \\
\hline Insulina basal (uU/ml) & 8.5 & 2.1 & 21 & 7.9 \\
\hline Insulina $60 \mathrm{~min}(\mathrm{uU} / \mathrm{ml})$ & 48.0 & 7.7 & 80.5 & 17.0 \\
\hline Insulina $120 \mathrm{~min}(\mathrm{uU} / \mathrm{ml})$ & 25.4 & 4.9 & 69.5 & 32.0 \\
\hline Insulina $180 \mathrm{~min}(\mathrm{uU} / \mathrm{ml})$ & 6.8 & 5.0 & 25 & 19.8 \\
\hline
\end{tabular}

*Abbreviations: SD, Standard deviation.

\section{Cutoff Values}

Statistical analysis resulted in cutoff for HOMA-IR (2.49), using the Youden index, the ROC curve, the average of two standard deviation and population 25th percentile, resulted en $72 \%$ for HOMA$\%$ BS and $64 \%$ for HOMA-\% IS. The selected population was distributed by sex and 
age range (20 to 35,36 to 45 and 46 to 65 years), and after setting a cut-off value of the mean plus two standard deviations, the data were subjected to one-way ANOVA. To determine significance, if $p \leq$ 0.05 the cut-off points for the subgroup were not significant relative to the overall cut-off point for the entire population. The selected population was distributed by sex and age range to establish the 25th percentile as the lower cut-off point for \% BS. These data were subjected to one-way ANOVA to determine significance at $p \leq$ 0.05 , and the subgroup cut-offs were not significantly different from the population cut-off point.

\section{Calculated Values for the Cons- truction of a Theoretical Chart to Classify Patients in Aguascalientes}

To classify patients undergoing a HOMA test as proposed by Graciela Buccini et al. ${ }^{15}$, different combinations of glucose and insulin determinations were performed to attain the same HOMA-IR. Thus, calculations were obtained for five iso- $\mathrm{HO}$ MA: two were below the cut-off (2.49), and two were above it. We calculated the 4 iso-\% BS series in the same manner. One had a $\%$ BS below the cut-off $(72 \%)$, and two were above it. All calculations were grouped in Figure 3, and we constructed a chart that classifies patients receiving the $\mathrm{HOMA}$ test in Aguascalientes.

\section{Table 2}

Tables showing several constant iso-HOMA-IR for the construction of a theoretical chart that will be used to classify patients.

\begin{tabular}{|c|c|c|c|c|c|c|c|c|c|c|c|c|c|c|}
\hline \multirow{10}{*}{ HOMA 0.59} & GLU & INS & \%BS & $\% / 15$ & \multirow{10}{*}{ HOMA 1.61} & GLU & INS & $\% B S$ & Q/S & & & & & \\
\hline & 70 & 3.3984 & 174.774857 & 169.491525 & & 70 & 9.2736 & 476.928 & 62.1118012 & & & & & \\
\hline & 80 & 2.9736 & 62.9703529 & 169.491525 & & 80 & 8.1144 & 171.834353 & 62.1118012 & & & & & \\
\hline & 90 & 2.6432 & 35.2426667 & 169.491525 & & 90 & 7.2128 & 96.1706667 & 62.1118012 & & & & & \\
\hline & 100 & 2.37888 & 23.1458595 & 169.491525 & & 100 & 6.49152 & 63.1607351 & 62.1118012 & & & & & \\
\hline & 110 & 2.16261818 & 16.564735 & 169.491525 & & 110 & 5.90138182 & 45.2020735 & 62.1118012 & & & & & \\
\hline & 120 & 1.9824 & 12.5204211 & 169.491525 & & 120 & 5.4096 & 34.1658947 & 62.1118012 & & & & & \\
\hline & 150 & 1.58592 & 6.56242759 & 169.491525 & & 150 & 4.32768 & 17.9076414 & 62.1118012 & \multirow{8}{*}{ HOMA 2.49} & 70 & 14.3424 & 737.609143 & 40.1606426 \\
\hline & 160 & 1.4868 & 5.51802062 & 169.491525 & & 160 & 4.0572 & 15.0576495 & 62.1118012 & & 80 & 12.5496 & 265.756235 & 40.1606426 \\
\hline & 170 & 1.39934118 & 4.70806377 & 169.491525 & & 170 & 3.81854118 & 12.8474283 & 62.1118012 & & 90 & 11.1552 & 148.736 & 40.1606426 \\
\hline \multirow{9}{*}{ HOMA 3.94} & GLU & INS & \%BS & $\% 15$ & \multirow{9}{*}{ HOMA 5.49} & GLU & INS & \%BS & $\% 15$ & & 100 & 10.03968 & \begin{tabular}{|l|}
97.683373 \\
\end{tabular} & 40.1606426 \\
\hline & 70 & 22.6944 & 1167.14057 & 25.3807107 & & 70 & 31.6224 & 1626.29486 & 18.2149362 & & 110 & 9.12698182 & \begin{tabular}{|c|}
69.9087969 \\
\end{tabular} & 40.1606426 \\
\hline & 110 & 14.4418909 & 110.618739 & 25.3807107 & & 110 & 20.1233455 & \begin{tabular}{|l|}
154.136263 \\
\end{tabular} & 18.2149362 & & 150 & 6.69312 & \begin{tabular}{|l|}
27.695669 \\
\end{tabular} & \begin{tabular}{|l}
40.1606426 \\
\end{tabular} \\
\hline & 120 & 13.2384 & 83.6109474 & 25.3807107 & & 120 & 18.4464 & 116.503579 & 18.2149362 & & 160 & 6.2748 & 23.2879175 & \begin{tabular}{|l|l|}
40.1606426 \\
\end{tabular} \\
\hline & 130 & 12.2200615 & 65.6600321 & 25.3807107 & & 130 & 17.0274462 & 91.4907555 & 18.2149362 & & 170 & 5.90569412 & \begin{tabular}{|l|}
19.8696251 \\
\end{tabular} & 40.1606426 \\
\hline & 140 & 11.3472 & \begin{tabular}{|l|}
53.0518442 \\
\end{tabular} & 25.3807107 & & 140 & \begin{tabular}{|l|}
15.8112 \\
\end{tabular} & \begin{tabular}{|l|}
73.9224935 \\
\end{tabular} & 18.2149362 & & & & & \\
\hline & 150 & 10.59072 & \begin{tabular}{|l|l|}
43.823669 \\
\end{tabular} & 25.3807107 & & 150 & 14.75712 & 61.0639448 & 18.2149362 & & & & & \\
\hline & 160 & 9.9288 & 36.8491546 & 25.3807107 & & 160 & 13.8348 & 51.3456495 & 18.2149362 & & & & & \\
\hline & 170 & 9.34475294 & 31.4402903 & 25.3807107 & & 170 & 13.0209882 & 43.8089324 & 18.2149362 & & & & & \\
\hline
\end{tabular}




\section{Table 3}

Tables showing several constant iso-HOMA-\%BS for the construction of a theoretical chart that will be used to classify patients.

\begin{tabular}{|c|c|c|c|c|c|c|c|c|c|}
\hline \multirow{12}{*}{$\% B S 40$} & GLU & INS & HOMA & \%IS & \multirow{12}{*}{ \%BS 72} & GLU & INS & HOMA & $\% 15$ \\
\hline & 70 & 0.77777778 & 0.13503086 & 740.571429 & & 70 & 1.4 & 0.24305556 & 411.428571 \\
\hline & 80 & 1.88888889 & 0.37477954 & 266.823529 & & 80 & 3.4 & 0.67460317 & 148.235294 \\
\hline & 90 & 3 & 0.66964286 & 149.333333 & & 90 & 5.4 & 1.20535714 & 82.962963 \\
\hline & 100 & 4.11111111 & 1.01962081 & 98.0756757 & & 100 & 7.4 & 1.83531746 & 54.4864865 \\
\hline & 110 & 5.22222222 & 1.4247134 & 70.1895551 & & 110 & 9.4 & 2.56448413 & 38.9941973 \\
\hline & 120 & 6.33333333 & 1.88492063 & 53.0526316 & & 120 & 11.4 & 3.39285714 & 29.4736842 \\
\hline & 130 & 7.44444444 & 2.4002425 & 41.6624569 & & 130 & 13.4 & 4.32043651 & 23.1458094 \\
\hline & 140 & 8.55555556 & 2.97067901 & 33.6623377 & & 140 & 15.4 & 5.34722222 & 18.7012987 \\
\hline & 150 & 9.666666667 & 3.59623016 & 27.8068966 & & 150 & 17.4 & 6.47321429 & 15.4482759 \\
\hline & 160 & 10.7777778 & 4.27689594 & 23.3814433 & & 160 & 19.4 & 7.6984127 & 12.9896907 \\
\hline & 170 & 11.8888889 & 5.01267637 & 19.9494228 & & 170 & 21.4 & 9.02281746 & 11.0830126 \\
\hline \multirow{12}{*}{ \%BS 100} & GLU & INS & HOMA & $\%$ IS & \multirow{12}{*}{ \%BS 150} & GLU & INS & HOMA & \%IS \\
\hline & 70 & 1.94444444 & 0.33757716 & 296.228571 & & 70 & 2.916666667 & 0.50636574 & 197.485714 \\
\hline & 80 & 4.72222222 & 0.93694885 & 106.729412 & & 80 & 7.08333333 & 1.40542328 & 71.1529412 \\
\hline & 90 & 7.5 & 1.67410714 & 59.7333333 & & 90 & 11.25 & 2.51116071 & 39.8222222 \\
\hline & 100 & 10.2777778 & 2.54905203 & 39.2302703 & & 100 & 15.4166667 & 3.82357804 & 26.1535135 \\
\hline & 110 & 13.0555556 & 3.56178351 & 28.0758221 & & 110 & 19.5833333 & 5.34267526 & 18.7172147 \\
\hline & 120 & 15.8333333 & 4.71230159 & 21.2210526 & & 120 & 23.75 & 7.06845238 & 14.1473684 \\
\hline & 130 & 18.6111111 & 6.00060626 & 16.6649828 & & 130 & 27.9166667 & 9.00090939 & 11.1099885 \\
\hline & 140 & 21.3888889 & 7.42669753 & 13.4649351 & & 140 & 32.0833333 & 11.1400463 & 8.97662338 \\
\hline & 150 & 24.1666667 & 8.9905754 & 11.1227586 & & 150 & 36.25 & 13.4858631 & 7.41517241 \\
\hline & 160 & 26.9444444 & 10.6922399 & 9.35257732 & & 160 & 40.4166667 & 16.0383598 & 6.23505155 \\
\hline & 170 & 29.7222222 & 12.5316909 & 7.9797691 & & 170 & 44.5833333 & 18.7975364 & 5.31984607 \\
\hline
\end{tabular}

By plotting each of the calculated values, we obtained a similar chart to that presented by Buccini et al. ${ }^{15}$ The area considered normal is delimited by $\left(^{*}\right)$. The upper cut-off point for HOMA-IR $=2.49$, and the lower value of $72 \%$ was used for HOMA-\%BS (green line). Several areas have been marked with a black frame.

In these areas, sector 1 is above the red line representing the highest HOMA-IR and above the line representing HOMA$\% \mathrm{BS}$. This pattern corresponds to increased insulin resistance with increasing \% BS or compensatory insulin secretion; this is the first manifestation of insulin resistance and suggest that it is important to pay more attention in the patients whose HOMA measurement is in this area.

In sector 2, insulin resistance is observed with diminishing beta secretion, and three subtypes can be identified based on the degree of hyperglycemia; the diminishing beta secretion in combination with insulin resistance appears in advanced stages before diabetes mellitus, and it is caused for a direct damage in beta cell produced by toxic effects of glucose and lipids. Sector 3 corresponds to compensatory increased beta-secretion but with normal insulin resistance; this increase even with normal glycemia and insulin appears in the inicial stages of truly insulin resistance.

Finally, sector 4 is delimited by normal insulin resistance but decreased beta-secretion, and means hyperglycemia. This sector may be classified depending on the degree of hyperglycemia( $4 a, 4 b$ and $4 c)$. A sub sector (4d) was found that has regular insulin resistance without hyperglycemia as well as decreased beta secretion, which is considered a state of pre-diabetes or high insulin sensitivity. 


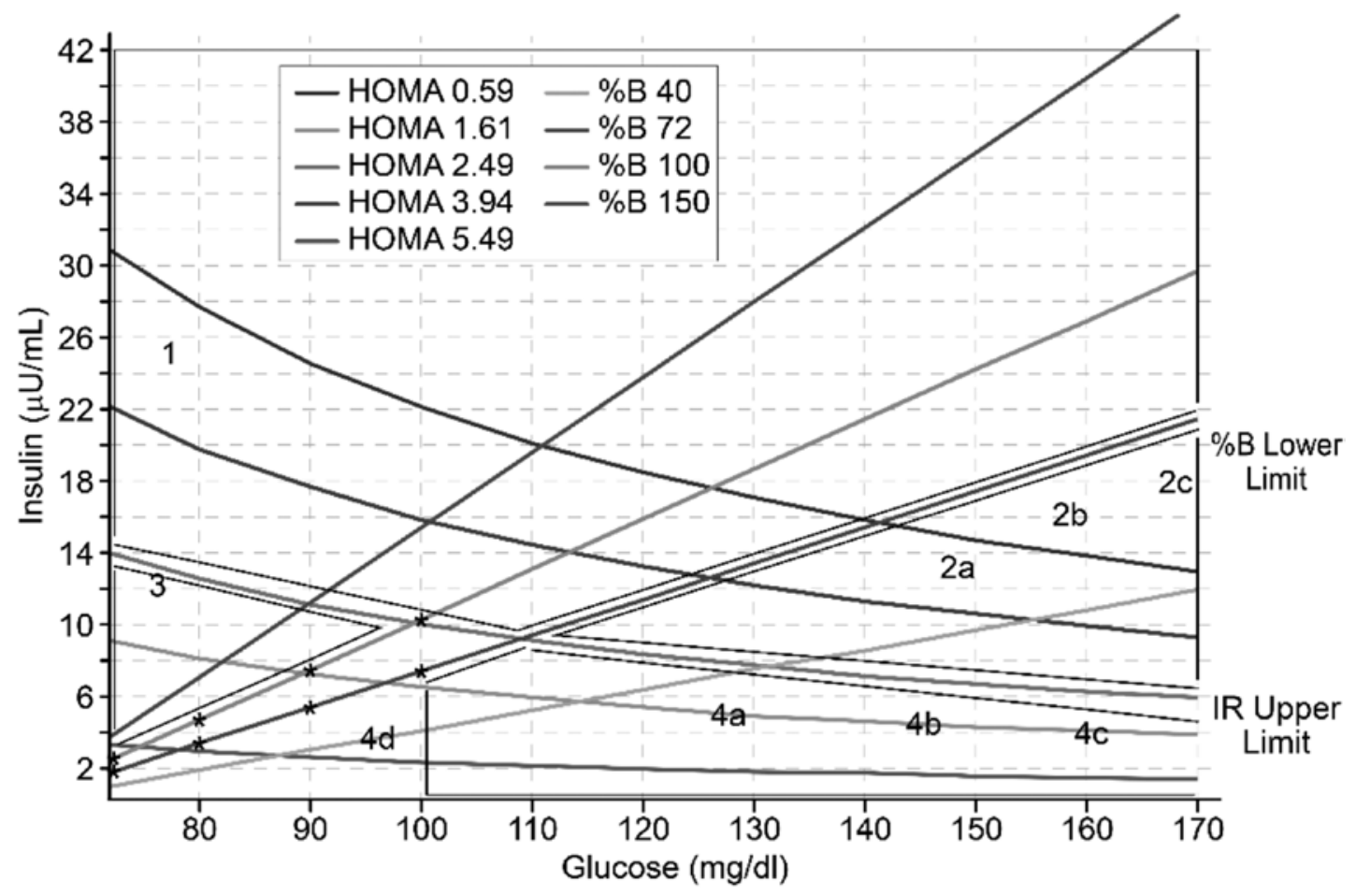

Figure 2. Chart prepared by different ISO-HOMA-IR and ISO-HOMA-\%BS

\section{Sensitivity and Specificity of the Homa Test in the Population of Aguascalientes}

When analyzing the cases by a validated diagnostic test, the total population was defined in the true positive characteristic cases. Sick patients were identified by a validated standard and positive HOMAIR (greater than 2.49), and 525cases were found. Healthy patients whose HOMA-IR was above the cut-off were considered false positives, and there were 13 such cases. Those patients who were classified as healthy by a validated standard and whose HOMA-IR was below the cut-off point established for the population were considered true negatives, and there were 535 such patients in total. Finally, those patients who showed disease evidenced by the diagnostic standard and whose HOMA-IR was below the cut-off point were considered false negatives, and there were 23 such cases. The data were entered into the GraphPad Prism 5.01 data analysis program, and the following parameters were obtained for the HOMA-IR cut-off = (mean + 2 SD) $2 .{ }^{49}$.

We found that for our population ( $\mathrm{n}=$ 548), all of the healthy patients in the municipality of Aguascalientes, as determined by a validated standard (glucose tolerance test with insulin determination at 60, 120 and 180 minutes) and considering a $\mathrm{HO}$ MA-IR cut-off point of 2.49 , had95.8\% sensitivity, $97.62 \%$ specificity, $97.58 \%$ positive predictive value, $95.87 \%$ negative predictive value, $40.25 \%$ positive likelihood ratio and a $0.043 \%$ negative likelihood ratio, with an area under the $\mathrm{ROC}$ curve of 0.9877 , assuming $p \leq 0.0001$ and a $95 \%$ confidence interval from 0.982 to 0.9935 . 


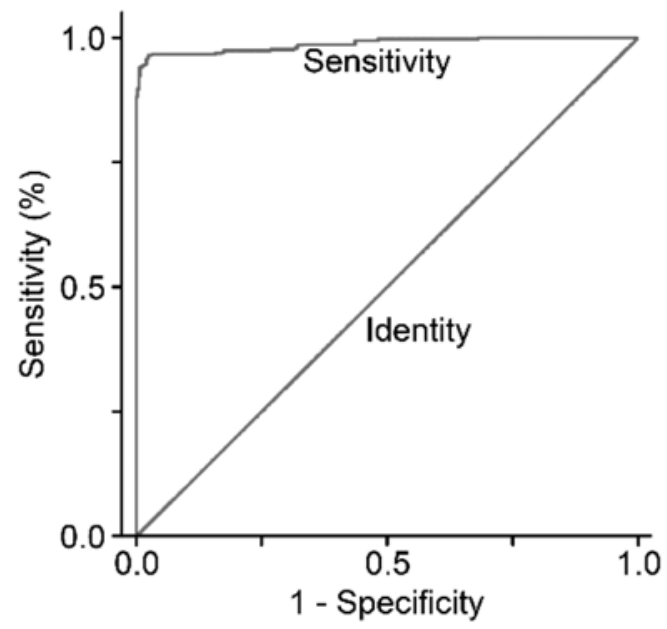

Figure 3. ROC curve showing sensitivity and specificity for the people of Aguascalientes with a cut-off point of 2.49 .

\section{Study on the Population with} insulin resistance

$A$ validated standard was used to conduct a study on glucose and HOMA-IR in the population; for individuals with insulin resistance, a Pearson's test was conducted to determine the correlation between glucose and HOMA-IR, and there was a significant correlation with $r=0.199$ and $p<0.0001$.

The percentiles for HOMA-IR and glucose were established for the population with insulin resistance, and a percentile in which the glucose variable would meet the criteria of glucose intolerance and diabetes mellitus according to the ADA criteria was sought $(125 \mathrm{mg} / \mathrm{dl}>$ glucose $>100 \mathrm{mg} / \mathrm{dl}$ and glucose $\geq 126 \mathrm{mg} / \mathrm{dl}$, respectively,). In our population, a glucose level> 100 is in the $30 \%$ percentile, and in contrast with the HOMA-IR for the population, this percentile corresponds to 3.6. Likewise, glucose $\leq 125$ is in the $77 \%$ percentile, in contrast to the population HOMA-IR, which is 5.78. A glucose level $\geq 126$ corresponds to the $78 \%$ percentile and is in contrast with the HOMA-IR, which corresponds to the 5.8 percentile. Therefore, we consider a patient to be intolerant to glucose when the HOMA-IR is between 3.6 to 5.78 and to have diabetes when the HOMA-IR is 5.8 . 


\section{Table 4}

Percentile distribution of HOMA-IR variables and glucose-insulin-resistant from a gold standard population.

\begin{tabular}{|c|c|c|c|c|c|c|c|c|}
\hline & IR Female & IR Female & IR Female & IR Male & IR Male & IR Male & Population & Population \\
\hline & $20-34$ & $35-49$ & $50-65$ & $20-34$ & $35-49$ & $50-65$ & HOMA-IR & glucose \\
\hline $\mathrm{N}$ & 91 & 97 & 145 & 49 & 79 & 87 & 548 & 548 \\
\hline $\begin{array}{l}22 \% \\
\text { percentil }\end{array}$ & 3.225 & 3.533 & 3.141 & 3.25 & 3.498 & 3.448 & 3.404 & 98 \\
\hline $\begin{array}{l}25 \% \\
\text { Percentil }\end{array}$ & 3.401 & 3.674 & 3.313 & 3.391 & 3.498 & 3.491 & 3.487 & 99 \\
\hline $\begin{array}{l}30 \% \\
\text { percentil }\end{array}$ & 3.509 & 3.713 & 3.457 & 3.833 & 3.602 & 3.713 & 3.6 & 101 \\
\hline Media & 3.852 & 4.433 & 3.947 & 4.479 & 4.113 & 4.167 & 4.167 & 108 \\
\hline $\begin{array}{l}75 \% \\
\text { Percentil }\end{array}$ & 4.719 & 6.071 & 5.632 & 6.061 & 5.667 & 5.51 & 5.639 & 123 \\
\hline $\begin{array}{l}77 \% \\
\text { percentil }\end{array}$ & 4.762 & 6.201 & 5.639 & 6.108 & 5.667 & 5.635 & 5.78 & 125 \\
\hline $\begin{array}{l}78 \% \\
\text { percentil }\end{array}$ & 4.762 & 6.366 & 5.639 & 6.143 & 5.671 & 5.745 & 5.805 & 129 \\
\hline $\begin{array}{l}\text { Multiple } \\
\text { comparison } \\
\text { test of } \\
\text { Dunnett }\end{array}$ & $\begin{array}{c}\text { Population } \\
\text { HOMA-IR } \\
\text { Vs IR Female } \\
20-34\end{array}$ & $\begin{array}{c}\text { Population } \\
\text { HOMA-IR } \\
\text { Vs IR Female } \\
35-49\end{array}$ & $\begin{array}{c}\text { Population } \\
\text { HOMA-IR } \\
\text { Vs IR Female } \\
50-65\end{array}$ & $\begin{array}{c}\text { Population } \\
\text { HOMA-IR } \\
\text { Vs IR Male } \\
20-34\end{array}$ & $\begin{array}{c}\text { Population } \\
\text { HOMA-IR } \\
\text { Vs IR Male } \\
35-49\end{array}$ & $\begin{array}{c}\text { Population } \\
\text { HOMA-IR } \\
\text { Vs IR Male } \\
50-65\end{array}$ & - & - \\
\hline $\begin{array}{l}\text { Significance } \\
\text { if } \\
P<0.05\end{array}$ & No & No & No & No & No & No & - & - \\
\hline
\end{tabular}

\section{Discussion}

The HOMA-IR model has been widely used in epidemiological studies to estimate insulin resistance. This model assumes that fasting blood glucose is regulated by the liver production of glucose, which is insulin-dependent; like wise, fasting insulin depends on the response of beta cells to glucose. The HOMA-IR formula should be validated in a population in which genetic and environmental factors are considered to take it into clinical practice 16 . The ideal method for analyzing the HOMA formula is the hyperinsulinemic-euglycemic clamp, which is difficult to use in clinical laboratories ${ }^{17}$.

The insulin resistance measured by the HOMA formula correlates closely with cardiovascular risk factors and precedes type 2 diabetes; it is therefore a predictor of the condition. It is known that insulin levels are a good surrogate marker of insulin resistance, and a HOMA value of 2.5 is associated with cardiovascular disease risk, while a value of 3.5 is associated with a risk of type 2 diabetes ${ }^{18}$.

The HOMA formula has been validated as determining insulin resistance, although there is no overall cut-off value. Therefore, it is necessary to validate a cut-off in each population ${ }^{19}$. It is important to consider the high range of cut-offs that many researchers have proposed. To compare these points extrapolated to our population with a $95 \%$ confidence interval, we should determine the sensitivity, specificity and positive likelihood ratio that these values would have in our community to classify our cut-offas reliable. 
Lee et al. ${ }^{20}$ studied 976 Korean subjects aged between 30 and 79 years and reported a cut-off of 2.34, which in our population would have $96.72 \%$ sensitivity, $95.26 \%$ specificity and a $20.38 \%$ positive likelihood ratio. These results are very similar to ours. However, our project, with a cut-off of 2.49, has a PLR of 40.26, and the age range was similar to ours. This cut-offpoint could be rated as good in our community.

Yeni-Komshian et al. ${ }^{21}$ presented a paper studying 490 Spaniards aged between 17 and 70 years and found a cut-off of 2.7 , which in our population would have $93.61 \%$ sensitivity, $99.71 \%$ specificity and good diagnostic value.It has $128.5 \%$ of the PLR, and therefore, this cut-off value is rejected as a safe cut-off option for our population.

Pozzan et al. ${ }^{22}$ presented a study in Rio de Janeiro, in which they evaluated 2,264 Brazilian subjects aged between 4 and 93 years andreportedtwocut-off points. The first cut-off was allocated to those under 18 years of age, being 2.39 for our population. It had $96.72 \%$ sensitivity and $96.16 \%$ specificity as well as $25.24 \%$ PLR; this cut-off point would be considered excellent in our population, although the age range for this cut-offis not similar to that of our patients.

In contrast, the authors of that study described an optimal cut-off value of 3.2 for their patients more than 18 years, which would give a cut-off point sensitivity of $82.85 \%$ and $100 \%$ specificity for our population. This value is useful to diagnose patients with disease, but it would lead to patients with early stages of insulin resistance not being properly diagnosed. It is important to consider that the PLR would be $>483 \%$, which makes it a cut-off point with low sensitivity.

The study conducted by Bonora et al. ${ }^{23}$ was based on the analysis of 225 Italians aged between 40 and 79 years in whom, when considering the last quintile, the $\mathrm{HO}$ MA-IR cut-offwas 2.77.Compared to our population, this population would have $92.37 \%$ sensitivity and $99.22 \%$ specificity, which are good values. ??Even so, a $126.5 \%$ PLR should be considered, as it would not be a reliable cut-off in our population.

In Argentina, Coniglio ${ }^{24}$ studied 135 patients aged between 40 and 60 years and reported a cut-off of 3.1. When compared to our population, it showed $86.31 \%$ sensitivity, $100 \%$ specificity and a PLR higher than $483 \%$, which makes it inaccuratefor our population.

Esteghamati et al. ${ }^{25}$ studied 3,071 Iranians aged between 25 and 64 and reported a cut-off of 1.8. When compared to our population, it showed $97.63 \%$ sensitivity, $71.72 \%$ specificity and a very good PLR of 3.36.This cutoff is good for defining healthy patients but not discriminating healthy patients from sick patients.

Gurmendia et al. ${ }^{26}$ reported a cut-off of 2.5 after studying 1,003 Chilean patients older than 80 years. Their cut-off was the same as our despite the age range difference between the two studies. When compared with our population, the findings were 95.8\% sensitivity, $97.81 \%$ specificity and PLR of 43.85 , which is slightly higher than what wasreported by our group.

Esteghamati et al. ${ }^{25}$ also described, in their study with 3,071 Iranian subjects, an optimal diagnostic cut-off of diabetes patients by HOMA and a proposed a cut-off of 4.33. This cut-off was 5.8 in our population based on a percentile comparison, where the existing correlation of the $\mathrm{HO}$ MA-IR result with glucose in a population of type 2 diabetes patients was previously confirmed by the Pearson's test $(r=0.2$ $p<0.0001$ ). Rossana 27, in their study, described a correlation between glucose and the HOMA-IR cut-off with a Pearson's correlation coefficient of $(r=0.52, p<$ 0.0001). 
We believe that establishing a safe cutoff in the population of Aguascalientes is necessary. Currently, many people who undergo a test to diagnose type 2 diabetes mellitus choose a simple fasting glucose test, and when normal values are found, the patient trusts the outcome. It is necessary to remember, however, that abnormal fasting glucose will appear 10 years after a self-regulating mechanism such as hyperinsulinemia has been triggered.

A basal insulin study can be suggested at the same time as a fasting glucose test, and it has more diagnostic value when the
HOMA formula is calculated, as indicators will give a real picture of what is happening with endogenous hepatic glucose production, insulin sensitivity in peripheral tissues, etc. However, we should remember that in the early stages of insulin resistance, aerobic exercise induces muscles to continue the carbohydrate metabolic pathway, and innovative studies report that exercise increases the amount of CAMP within the cell. This $C A M P$ is essential in mobilizing vesicles containing the Glut-4 channels for glucose uptake into the cell ${ }^{28}$.

\section{Conclussions}

In summary, the following conclusions can be drawn:

1. The cut-off value for the upper HOMA-IR range in our population of $n=548$ patients aged between 20 and 65 years with no evidence of metabolic syndrome, and using the Youden index by ROC curve, the population mean plus two standard deviations was 2.49, and it is considered normal. The cut-offs for the lower HOMA-\%BS and HOMA-\% IS ranges, considering the 25th percentile, were $72 \%$ and $64 \%$, respectively.

2. With a HOMA-IR cut-off of 2.49 in the study population, reported values were 95.8\% sensitivity, $97.62 \%$ specificity, $97.58 \%$ PPV, 95.87\% NPV, 40.25\% PLR and $0.043 \%$ NLR with an area under the ROC curve of 0.9877 .

3. Glucose intolerance is considered to exist by percentile correlation if HOMA-IR $>3.6$ (30\% percentile) but $<5.78$ (77\% percentile). Diabetes mellitus is considered to exist in a patient if HOMA-IR is $>5.8$ (78\% percentile).

4. The HOMA formula in the study population $(n=548)$ is a diagnostic and screening test with good sensitivity and specificity for the diagnosis of insulin resistance.

\section{Bibliografía}

1. Saini V. Molecular mechanisms of insulin resistance in type 2 diabetes mellitus. World J Diabetes 2010;1:68-75.

2. De los Ríos Castillo JL, Sánchez Sosa JJ, Barrios Santiago P, Guerrero Sustaita V. Calidad de vida en pacientes con diabetes mellitus tipo 2 [Quality of life in patients with type 2 diabetes mellitus].Rev Med Inst Mex Seguro Soc 2004;42:109-116.

3. Wild S, Roglic G, Green A, Sicree R, King H. Glo- bal Prevalence of Diabetes: Estimates for the year 2000 and projections for 2030. Diabetes Care 2004;27:1047-1053.

4. Reaven G. Role of Insulin Resistance in Human Disease. Diabetes 1988;37:1595-1607.

5. Shanik $M, X u Y$, ?krha J, Dankner R, Zick $Y$, Roth J. Insulin Resistance and Hyperinsulinemia: Is hyperinsulinemia the cart or the horse? Diabetes Care 2008;31:S262-S268

6. Meigs J, Rutter $M$, Sullivan $L$, Fox $C$, D'Agostino $R$, Wilson P. Impact of Insulin Resistance on Risk 
of Type 2 Diabetes and Cardiovascular Disease in People With Metabolic Syndrome. Diabetes Care 2007;30:1219-1225.

7. Abdul-Ghani $M$, Tripathy D, DeFronzo R. Contributions of ?-Cell Dysfunction and Insulin Resistance to the Pathogenesis of Impaired Glucose Tolerance and Impaired Fasting Glucose. Diabetes Care 2006;29:1130-1139.

8. DeFronzo R, Tobin J, Andres R. Glucose clamp technique: a method for quantifying insulin secretion and resistance. Am J Physiol 1979;237:E214-E223.

9. Greenfield MS, Doberne L, Kraemer F, Tobey T, Reaven G. Assessment of Insulin Resistance with the Insulin Suppression Test and the Euglycemic Clamp. Diabetes 1981;30:387-392.

10. Lundbaek K. Intravenous Glucose Tolerance as a Tool in Definition and Diagnosis of Diabetes Mellitus. BMJ 1962;1:1507-1513.

11. Saad $M$, Anderson R, Laws A, Watanabe $R$, Kades W. A Comparison betweenthe Minimal Model and the Glucose Clamp in the Assessment of Insulin Sensitivity Across the Spectrum of Glucose Tolerance. Diabetes 1994;43:1114-1121.

12. Bergman RN. Toward Physiological Understanding of Glucose Tolerance: Minimal-Model Approach. Diabetes 1989;38:1512-1527.

13. Matthews DR, Hosker JR, Rudenski AS, Naylor BA, Treacher DF, Turner RC. Homeostasis model assessment: insulin resistance and ?-cell function from fasting plasma glucose and insulin concentrations in man. Diabetologia 1985;28:412-419.

14. Levy JC, Matthews DR, Hermans ME. Correct Homeostasis Model Assessment (HOMA) Evaluation Uses the Computer Program. Diabetes Care 1998;21:2191-2192.

15. Buccini Graciela S, Wolftbal DL. Valores de corte para índices de insulinoresistencia, insulinosensibilidad, e insulinosecrecion, derivados de la fórmula de homa y del programa homa2, interpretación de los datos [Cutoffs ??for the indices of insulin resistan$\mathrm{ce}$, insulin sensitivity, and insulin secretion derived from the HOMA formula and the HOMA2 program, data interpretation].Rev Argent Endocrinol Metab 2008;45:7-16.

16. Defronzo R, Tobin J, Andres R. Glucose clamp technique: a method for quantifying insulin secretion and resistance. Am J Physiol 1979;237:214-230.

17. Vasques AC, Rosado LE, De Cassia GR, Geloneze B. Critical analysis on the use of the homeostasis model assessment (HOMA) indexes in the evaluation of the insulin resistance and the pancreatic beta cells functional capacity. Arq Bras Endocrinol Metabol 2008;52:32-39.

18. García-Fuentes E, Garrido-Sánchez L, Tinahones FJ. Evaluación de la sensibilidad a la insulina en investigación y en la práctica clínica: Aplicaciones prácticas Homeostatic Model Assessment (HOMA) [Assessment of insulin sensitivity in research and in clinical practice: Homeostatic Model Assessment (HOMA) practical applications].Avances en Diabetología2008;24:291-295

19. Hernández JA, Tuero IA, Vargas D. Utilidad del índice HOMA-IR con una sola determinación de insuli- nemia para diagnosticar resistencia insulínica [Utility of HOMA-IR with a single insulin measurement to diagnose insulin resistance]. Revista Cubana de Endocrinología 2011;22:69-77.

20. Turner R, Holman RR, Matthews D, Hockaday TR, Peto J. Insulin deficiency and insulin resistance interaction in diabetes: estimation of their relative contribution by feedback analysis from basal plasma insulin and glucose concentrations. Metabolism 1979;28:1086-1096.

21. Yeni-Komshian $H$, Carantoni $M$, Abbasi $F$, Reaven $G M$. Relationship between several surrogate estimates of insulin resistance and quantification of insulinmediated glucose disposal in 490 healthy nondiabetic volunteers. Diabetes Care 2000;23:171-175.

22. Pozzan R, Brandão AA, Magalhães MEC, Brandão AP. Insulin and HOMA Níveis em uma cidade da amostra do Rio de Janeiro [Insulin and HOMA levels in a sample population in Rio de Janeiro].Revista da SOCERJ 2003;16:75-85.

23. Bonora E, Kiechl S, Willeit J, Oberhollenzer F, Egger G, Targher G, Alberiche M, Bonadonna RC,Muggeo $M$. Prevalence of insulin resistance in metabolic disorders: the Bruneck Study. Diabetes. 1998;47:16431649.

24. Coniglio R, Pino $M$, Cailotto $M$, Colombo O, Selles J, Framarini S, Malaspina $M$, Salgueiro A, Otero JC, Alvarez C, Polini N, Vasquez L, Camardon H, Menendez $M$, Benozzi $L$, Kelly V. Epidemiología y prevención cardiovascular Indice de insulinorresistencia y síndrome metabólico en un grupo poblacional del sur argentino [Cardiovascular epidemiology and prevention. Insulin resistance index and metabolic syndrome in a population in southern Argentina].Revista argentina de cardiologia, 2000;68:1-11.

25. Esteghamatil $A$, Ashraf $H$, Khalilzadeh $O$, Zandieh A, Nakhjavani M, Rashidi A, HaghazaliM. Optimal cut-off of homeostasis model assessment of insulin resistance (HOMA-IR) for the diagnosis of metabolic syndrome: third national surveillance of risk factors of non communicable diseases in Iran. SuRFNCD $-2007$.

26. Garmendia ML, Lera L, Sanchez $H$, Uauy $R$, Albala $C$. Valores normativos de resistencia a la insulina mediante HOMA-IR en adultos mayores de Santiago de Chile [Standard values ??of insulin resistance using HOMA-IR in older adults of Santiago, Chile]. Rev Méd Chil2009;137:1409-1416.

27. Baracco R, Mohanna S, Seclen S. Determinación de la sensibilidad a la insulina usando el método HOMA en poblaciones adultas habitantes de grandes alturas y a nivel del mar [Determination of insulin sensitivity using HOMA in adults at high altitudes and at sea level].Revista Médica Herediana2006;17:206-212.

28. Rojas J, Bermúdez V, Leal E, Cano R, Luti Y, Acosta L, Finol F, Aparicio D, Arraiz N, Linares S, Rojas E, Canelon R, Sanchez D. Insulinorresistencia e hiperinsulinemia como factores de riesgo para enfermedad cardiovascular [Insulin resistance and hyperinsulinemia as risk factors for cardiovascular disease]. Archivos venezolanos de farmacología y terapéutica 2008;27:29-40. 